\title{
AVALIAÇÃO DE UMA DISCIPLINA DE INFORMÁTICA POR GRADUANDOS DE ENFERMAGEM
}

\author{
Margarita Antonia Villar Luis* \\ Fernando Antonio Moala** \\ Yolanda Dora Martinez Évora* \\ Carmen Gracinda Silvan Scochi* \\ Rosalina Aparecida Partezani Rodrigues*
}

\begin{abstract}
Este estudo teve como objetivo investigar a opinião dos alunos do primeiro ano de graduação em Enfermagem sobre a disciplina Informática Aplicada à Saúde. Os dados foram coletados através de um questionário com questões abertas e fechadas aplicadas em três anos consecutivos (1989, 1990, 1991). Os resultados mostraram que é importante a permanência da disciplina no Curso de Graduação em Enfermagem. As expectativas dos alunos relacionaram-se com a necessidade de familiarizarem-se com o computador. As críticas mencionadas foram quanto a necessidade de maior tempo e mais equipamentos para efetivar o processo de aprendizagem.
\end{abstract}

UNITERMOS: enfermagem, ensino, informática

\section{INTRODUÇÃO}

O computador vem tendo múltiplas aplicações na área da saúde iniciando com os grandes sistemas de informação hospitalar, evoluindo para o processamento de imagens e sinais, e sistemas de apoio à saúde. Nesse contexto sofisticado o profissional de enfermagem está inserido, pois, embora a informática não seja ainda uma realidade para a maioria das instituições de saúde, a tendência nesses serviços é o avanço da mesma (LEÃO \& SIGULEN, 1990).

*Professor Doutor da Escola de Enfermagem de Ribeirão Preto da Universidade de São Paulo

**Professor de Estatística da Faculdade de Filosofia, Ciências e Letras de Ribeirão Preto da Universidade de São Paulo 
Com isso, a familiarização do aluno desde o início da formação profissional, traz esclarecimentos dissipando mitos sobre o papel desempenhado pelo computador e também as atitudes negativas em relação a seu uso. Tal objetivo pode ser atingido, desenvolvendo formas de introduzir o computador para que destruam tais crenças e contribuam par a formação de percepções realistas, dando uma idéia clara das potencialidades e limitações da informática, mostrando ao aluno que o computador não é um fim em si mesmo, mas um instrumento para atingir outros objetivos, tais como preparar um relatório, elaborar um plano de cuidados, dentre outros (CYSNEIROS, 1991).

No Brasil, em 1986, o relatório da Comissão Especial de Informática em Saúde (SEI), do então Ministério da Ciência e Tecnologia citou a importância da inserção dos profissionais da área da saúde, no uso do computador. Esse documento, congregando opiniões dos mais diversos setores (profissionais de informática em saúde, órgãos prestadores de serviços e instituições acadêmicas), apontou diretrizes de um programa nacional para a área, incluindo aspectos dos serviços de saúde, assistência, pesquisa e a formação dos recursos humanos (BRASIL, 1988).

Os sistemas de informação gerenciais e clínicos são uma realidade no ambiente hospitalar e sua tendência nos próximos anos, é a evolução. Assim, usuários tais como administradores, médicos, enfermeiros e outros, solicitarão preparo e treino específicos, já que estarão manejando esses sistemas nas atividades de assistência ao paciente e na gerência institucional. A tomada de decisões adequadas, baseadas em informações confiáveis se constitui, no curto prazo, num fator de pressão externa para que a informática seja introduzida na formação desses profissionais (HELLER et al, 1985).

$\mathrm{Na}$ enfermagem, os microcomputadores foram utilizados, pela primeira vez na educação, nos Estados Unidos, em 1972. São reconhecidos, atualmente, como importantes instrumentos de ensino, devido aos benefícios proporcionados por suas capacidades, limitadas apenas pela criatividade do usuário, pela sua mobilidade e custo relativamente baixo quando comparado aos seus recursos, incluindo a habilidade para armazenar, manipular e processar informações. Nessa mesma década de setenta, no país citado, foi desenvolvido um estudo para identificar as necessidades dos profissionais de saúde no ensino da computação médica, conduzido sob os auspícios da Federação Internacional de Processamento de Informações. Nesta pesquisa, os países desenvolvidos concluíram que todos os enfermeiros deveriam ter um conhecimento geral sobre o uso do computador e processamento de dados e que esse conteúdo deveria ser incluído no currículo da enfermagem. O relatório elaborado sugeria, ainda, que um grande número de enfermeiros fosse educado para contribuir, efetivamente, no desenvolvimento de sistemas automatizados (HELLER et al, 1990; LARSON, 1987; MIRIN, 1981).

No que se refere ao Brasil, os problemas levantados no tocante à introdução da informática na educação de enfermagem, não parecem ser muito diferentes dos encontrados pelas investigadoras norte-americanas, contudo, trata-se de especulações, 
fruto da vivência, pois afirmações mais categóricas nesse âmbito, somente se forem obtidas através de investigações científicas.

Até o momento, sobre a utilização do computador em educação na enfermagem brasileira, tem-se de concreto algumas experiências do uso desse recurso em simulação no ensino de enfermagem na saúde do adulto, em banco de dados de possíveis prescrições de enfermagem por problemas identificados e na utilização da avaliação formativa no ensino de atenção primária (GUIMARÃES, 1988; SANTOS, 1992; VITALE, 1991).

A Escola de Enfermagem de Ribeirão Preto da Universidade de São Paulo (EERP-USP), desde 1986, dispõe de um setor centralizado de informática, que além de recursos materiais, conta com recursos humanos especializados (2 programadores e 1 analista de sistemas). Este setor tem fornecido assessoria, tanto na área administrativa, quanto no apoio direto aos usuários, sejam eles alunos (graduação e pós-graduação), docentes ou funcionários. Há ainda, um grupo de docentes, representando os três Departamentos da EERP-USP, que desde 1986, tem se dedicado à introdução da informática na Enfermagem, assumindo a responsabilidade de coordenar e ministrar cursos extracurriculares, bem como uma disciplina na graduação. Nessas atividades, o grupo tem contado com a colaboração dos técnicos especializados.

A disciplina "Informática Aplicada à Saúde" foi elaborada em 1988, tendo como objetivos: apresentar uma visão geral sobre o processamento de informação, difundir a cultura da informática e suas aplicações na área da saúde e familiarizar o aluno de enfermagem com o computador para que possa utilizá-lo na sua prática acadêmica e/ou profissional. É uma disciplina de caráter obrigatório, com carga horária de 45 horas e foi oferecida, pela primeira vez, aos alunos do primeiro ano, segundo semestre de 1989.

O conteúdo programático aborda alguns aspectos teóricos da informática e sua utilização na sociedade atual, componentes e funcionamento de um computador, aplicações e impactos da informática nas organizações de saúde e na prática de enfermagem, quando são introduzidos conceitos sobre programas aplicativos de uso geral (processador de textos, planilha eletrônica e um pacote estatístico) e softwares educativos.

Desde o início da implementação dessa disciplina, tinha-se em mente utilizar o computador com instrumento para criar espaços interdisciplinares e para definir uma rede de relações e significados entre as diversas disciplinas da graduação em enfermagem. Isso porque, a literatura a respeito da inserção da informática no ensino, adverte para o fato de que essa nova ciência não deve ser ensinada num vácuo, mas integrada com as demais disciplinas do currículo. Acresça-se que essa integração propiciaria um real florescimento da experiência em computação transformando-a num instrumento de ruptura das fronteiras tradicionais entre fragmentos do saber. É desejável ainda, que a informática no currículo escolar, não se torne uma disciplina isolada, pois isso contribui para que outros professores desistam de qualquer 
iniciativa própria para integrar a informática à sua prática pedagógica (LEFFA, 1991; VITALE, 1991).

Em concordância com essas colocações, a disciplina "Informática Aplicada à Saúde" buscou o entrosamento com outras disciplinas; em 1989, integrou-se com Estatística (pacote estatístico), em 1990 incluiu também a disciplina Instrumentos Básicos de Enfermagem, no módulo de Iniciação à Metodologia Científica onde era solicitado ao aluno que fizesse a análise de um trabalho científico, e apresentasse com um relatório final, no qual ele utilizava os recursos de computador.

Procedendo da mesma forma, em 1991, buscou-se a integração com a disciplina Saneamento e Vigilância Epidemiológica onde o aluno desenvolvia uma temática (orientada pelo professor), dentro de um processo de investigação científica, cabendo à disciplina de Instrumentos Básicos, orientar no tocante ao método científico. Quanto à disciplina de Estatística, esta orientava as formas de como processar os dados. Finalmente, a disciplina de Informática, fornecia os instrumentos necessários (processador de texto e gráficos) ao aluno, para apresentação do relatório final.

A avaliação do aluno tem sido realizada a partir do relatório final, onde cada uma das disciplinas envolvidas aprecia a parte que lhe diz respeito de acordo com os critérios que foram estabelecidos. Na disciplina Informática Aplicada à Saúde, os requisitos avaliados relacionam-se à utilização dos recursos apreendidos, considerando-se a criatividade e a estética na apresentação do trabalho.

Passados esses três anos, sentiu-se a necessidade de avaliar essa experiência de ensino, já que se tratava de uma nova disciplina no currículo de enfermagem, empreendimento novo em nível de Brasil e por isso, sem parâmetros disponíveis para fundamentar o conteúdo programático. Optou-se pela avaliação da disciplina frente aos objetivos propostos, a partir da opinião dos alunos que a cursaram, julgando que sua vivência forneceria subsídios necessários para essa avaliação.

Assim, o presente estudo se propõe a investigar a opinião dos alunos do curso de graduação em enfermagem, sobre a disciplina Informática Aplicada à Saúde.

\section{METODOLOGIA}

\subsection{População}

Nesses três anos, o total de alunos matriculados na referida disciplina, foi de 230; sendo que 59 pertencentes a 1989, 62 a 1990 e 109 à 1991. Utilizando-se uma técnica de amostragem, obteve-se uma população de 158 participantes distribuídos em três sub-amostras, incluindo elementos dos três anos. A amostra de 
1989 compreendeu 38 (64\%) alunos, a de 1990 abrangeu 50 (80,6\%) alunos e a amostra de 1991 contou com 70 (61,5\%) alunos, dos discentes inscritos na disciplina.

\subsection{Coleta de dados}

Para a coleta dos dados aplicou-se um questionário composto de perguntas fechadas e abertas, oferecido aos alunos ao término da disciplina. Esse instrumento contemplou três categorias de informação: a primeira solicitando dados que revelassem as características da população; a segunda, referindo-se à avaliação da disciplina, frente a temas gerais, tais como a importância atribuída, (indicada pelas justificativas para sua permanência ou não no currículo), a seleção do caráter (obrigatório ou optativa), e as expectativas dos alunos. Foi incluído também um espaço para que fossem apontadas as críticas à disciplina, segundo a opinião da população investigada. A terceira categoria solicitou do aluno, a apresentação de sugestões referentes à carga horária e distribuição entre teoria e prática, conteúdo e as estratégias de ensino na disciplina.

\subsection{Tratamento estatístico}

As questões fechadas foram tabuladas conforme procedimento habitual de contagem da freqüência. Já as questões abertas, exigiram a leitura atentiva no sentido de categorizar temas comuns, considerando como mais relevantes àqueles citados com maior freqüência pela população.

\section{RESULTADOS E DISCUSSÃO}

Os dados foram agrupados em três temáticas a fim de propiciar melhor compreensão dos resultados obtidos, os quais serão analisados e discutidos nos subitens que se seguem.

\subsection{Características da população}

No que se refere aos dados demográficos, a população investigada constituiuse predominantemente de mulheres, com 139 (88,0\%), e apenas $19(12,0 \%)$ homens. Quanto à idade, predominou a faixa etária de alunos menores de 20 anos com 79 (50\%) elementos seguida da faixa etária compreendida entre os 20 a 30 anos, com 59 $(37,3 \%)$. 
Cabe ressaltar ainda como característica dessa população, o fato de que 134 $(84,8 \%)$, dos alunos nunca operaram um computador, e os demais $24(15,1 \%)$ relataram experiência bastante diversificada (alguns sabiam apenas digitação e outros dominavam processadores de texto).

\subsection{Avaliação da disciplina}

A grande maioria dos alunos, ou seja, 156 (98,7\%) deles consideram uma iniciativa importante, a inclusão da disciplina no currículo da enfermagem. Tal posicionamento pode ser explicado através das diversas justificativas que os alunos emitiram sobre o assunto. Dos 158 alunos participantes do estudo 6 deles não apresentaram justificativa. As justificativas emitidas por 152 alunos, encontram-se relacionadas no Quadro 1.

QUADRO 1 - JUSTIFICATIVAS* APRESENTADAS PELOS ALUNOS SOBRE A INCLUSÃO DA DISCIPLINA DE INFORMÁTICA APLICADA À SAÚDE. RIBEIRÃO PRETO, 1993.

\begin{tabular}{|l|c|c|c|c|}
\hline \multicolumn{1}{|c|}{ JUSTIFICATIVAS } & $\begin{array}{c}1989 \\
\mathbf{n}\end{array}$ & $\begin{array}{c}1990 \\
\mathbf{n}\end{array}$ & $\begin{array}{c}1991 \\
\mathbf{n}\end{array}$ & $\begin{array}{c}\text { TOTAL } \\
\%\end{array}$ \\
\hline $\begin{array}{l}\text { Oferece mais oportunidade na } \\
\text { carreira ampliando o espaço de } \\
\text { atuação do enfermeiro. }\end{array}$ & 3 & 40 & 52 & $\begin{array}{c}95 \\
29,5\end{array}$ \\
\hline $\begin{array}{l}\text { Capacita o aluno para utilizar o } \\
\text { computador na prática de } \\
\text { enfermagem. }\end{array}$ & 14 & 33 & 32 & $\begin{array}{c}79 \\
24,5\end{array}$ \\
\hline $\begin{array}{l}\text { Proporciona atualização para } \\
\text { acompanhar o processo de } \\
\text { informatização da sociedade. }\end{array}$ & 11 & 25 & 20 & $\begin{array}{c}56 \\
17,4\end{array}$ \\
\hline $\begin{array}{l}\text { Integra a enfermagem com a } \\
\text { informática. }\end{array}$ & 1 & 27 & 26 & $\begin{array}{c}54 \\
16,8\end{array}$ \\
\hline Outras** & 3 & 21 & 14 & $\begin{array}{c}38 \\
11,8\end{array}$ \\
\hline TOTAL & $\mathbf{3 8}$ & 146 & 144 & $\begin{array}{c}328 \\
100,0\end{array}$ \\
\hline
\end{tabular}

* Houve alunos que expressaram mais de uma justificativa

** proporciona status - (3) 1989; (5) 1990; (1) 1991.

aumenta a eficiência - (10) 1990; (8) 1991.

melhora assistência ao paciente - (6) 1996; (5) 1991. 
Neste quadro constata-se primeiramente, que em geral, cada aluno expressou mais de uma justificativa, com uma média de 2,12 sendo que são apresentadas as quatro justificativas de maior freqüência. Dentre essas, destaca-se para a população estudada, aquela que se refere ao tema, "oferecimento de maiores oportunidades na carreira e ampliação do espaço de atuação do enfermeiro", representando 95 (29\%) das citações dos alunos; essa justificativa foi assinalada acentuadamente nas sub-amostras dos anos de 1990 e 1991.

A segunda maior freqüência se verifica na justificativa, "capacita o aluno para utilizar o computador na prática de enfermagem", com 79 (24\%) das menções, e, analisando-se isoladamente as três sub-amostras, percebe-se que essa justificativa apresenta freqüência elevada nos três anos, tendo predominado na referente ao ano de 1990. Como terceira justificativa mais mencionada, aparece aquela que diz respeito a "proporcionar atualização para acompanhar o processo de informatização na sociedade", com uma freqüência de 56 (17\%) das citações da população geral. Tendo apresentado também uma freqüência considerável nas três sub-amostras, especialmente em 1990. Segue-se, em termos de predomínio de citações, a justificativa, "integra a informática com a enfermagem, apresentando $54(16,5 \%)$, dentre a totalidade das justificativas feitas pelos alunos". Houve outras justificativas mencionadas, contudo, foram qualitativamente diferentes ("proporciona status", "aumenta a eficiência", "melhora a assistência ao paciente") e em número muito pequeno para formarem um grupo, como os já mencionados.

Outro aspecto relevante, que assinala, de forma indireta, a importância que a população estudada concede à disciplina, diz respeito à configuração de obrigatoriedade atribuída à mesma. Constata-se esse fato, em especial nas amostras de 1990 e 1991, onde a grande maioria, ou seja, 40 (80\%) alunos e $54(77 \%)$ alunos respectivamente, consideram que ela deve ser obrigatória. Exceção, à amostra de 1989, onde 19 (50\%) dos alunos consideraram que deveria ser uma disciplina optativa.

Quanto à avaliação propriamente dita da disciplina, considerou-se que ela surgiria a partir das expectativas anteriores que os alunos tinham antes de cursá-la. Além desse tópico, julgou-se que outros tais como, o relato das possíveis falhas ou críticas à disciplina, contribuiriam mais concretamente, como critérios para sua avaliação. Os dados referentes à esses tópicos, podem ser observados nos Quadros 2 e 3, respectivamente. 
QUADRO 2 - EXPECTATIVAS* DOS ALUNOS EM RELAÇÃO À DISCIPLINA INFORMÁTICA APLICADA À SAÚDE. RIBEIRÃO PRETO, 1993.

\begin{tabular}{|c|c|c|c|c|}
\hline EXPECTATIVAS & $\begin{array}{c}1989 \\
n\end{array}$ & $\begin{array}{c}1990 \\
n\end{array}$ & $\begin{array}{c}1991 \\
n\end{array}$ & $\begin{array}{c}\text { TOTAL } \\
\quad \%\end{array}$ \\
\hline Familiarizar-se com o computador & 10 & 33 & 33 & $\begin{array}{c}76 \\
40,4\end{array}$ \\
\hline $\begin{array}{l}\text { Esperava maior aprofundamento } \\
\text { no conteúdo teórico e/ou prático }\end{array}$ & 19 & 23 & 24 & $\begin{array}{c}66 \\
35,1\end{array}$ \\
\hline $\begin{array}{l}\text { Esperava ter mais horas para } \\
\text { praticar livremente no computador. }\end{array}$ & 7 & 21 & 1 & $\begin{array}{c}29 \\
15,4\end{array}$ \\
\hline $\begin{array}{l}\text { Esperava acompanhamento mais } \\
\text { direto (de monitores ou docentes). }\end{array}$ & 7 & 7 & 3 & $\begin{array}{l}17 \\
9,1\end{array}$ \\
\hline TOTAL & 43 & 84 & 61 & $\begin{array}{c}188 \\
100,0\end{array}$ \\
\hline
\end{tabular}

* Houve alunos que expressaram mais de uma expectativa

Foram emitidas um total de 188 expectativas pelos 141 alunos, no que concerne à disciplina; $76(40,4 \%)$ delas, dizem respeito à "familiarizar-se com o computador", portanto, parece que a disciplina atendeu em parte o esperado pelos alunos, já que houve além dessa, a manifestação isolada ou concomitante de outras. O "esperar maior aprofundamento no conteúdo", apareceu como uma expectativa, também, bastante freqüente, com 66 (35,1\%) das citações. As demais, "... ter mais horas para praticar no computador" e "...acompanhamento mais direto...", apresentaram uma freqüência de 29 $(15,4 \%)$ e $17(9,1 \%)$, respectivamente. Salienta-se ainda que quinze alunos se manifestaram como não tendo expectativas a priori, e outros dois, não responderam. 


\section{QUADRO 3 - CRÍTICAS FEITAS PELOS ALUNOS À DISCIPLINA INFORMÁTICA APLICADA À SAÚDE. RIBEIRÃO PRETO, 1993}

\begin{tabular}{|c|c|c|c|c|}
\hline CRÍTICAS & $\begin{array}{c}1989 \\
n\end{array}$ & $\begin{array}{c}1990 \\
n\end{array}$ & $\begin{array}{c}1991 \\
\mathrm{n}\end{array}$ & $\begin{array}{c}\text { TOTAL } \\
\%\end{array}$ \\
\hline $\begin{array}{l}\text { Muitos alunos nas aulas práticas; } \\
\text { sala pequena e número } \\
\text { insuficiente de instrutores e } \\
\text { equipamentos. }\end{array}$ & 6 & 38 & 52 & $\begin{array}{c}96 \\
30,7\end{array}$ \\
\hline Poucas aulas práticas & 4 & 29 & 46 & $\begin{array}{c}79 \\
25,2\end{array}$ \\
\hline $\begin{array}{l}\text { Conteúdo teórico sobre uso e } \\
\text { aplicações do computador foi } \\
\text { superficial. }\end{array}$ & 8 & 18 & 35 & $\begin{array}{c}61 \\
19,5\end{array}$ \\
\hline $\begin{array}{l}\text { Procedimentos didáticos não } \\
\text { foram adequados. }\end{array}$ & 7 & 9 & 10 & $\begin{array}{c}51 \\
16,3\end{array}$ \\
\hline $\begin{array}{l}\text { Aulas corridas e muito distante } \\
\text { uma das outras. }\end{array}$ & 16 & - & 178 & $\begin{array}{l}26 \\
8,3\end{array}$ \\
\hline TOTAL & 41 & 94 & 178 & $\begin{array}{c}313 \\
100,0\end{array}$ \\
\hline
\end{tabular}

* Houve alunos que expressaram mais de uma crítica

Pelo Quadro 3, nota-se que houve um total de 313 críticas, as quais abrangeram 5 temas principais, e que foram mencionadas pelos alunos, tanto de maneira isolada quanto concomitante, verificando-se, freqüentemente, que um mesmo aluno emitiu mais de uma crítica à disciplina, com média de 1,99.

A crítica mais contundente, com $96(30,7 \%)$ das citações referiu-se à existência de muitos alunos nas aulas práticas e número insuficiente de instrutores e equipamentos. Vem a seguir a queixa sobre a insuficiência de aulas práticas com $79(25,2 \%)$ das menções dos alunos. Outras críticas, mencionadas pelos alunos, dizem respeito à superficialidade do conteúdo teórico em geral e aos procedimentos didáticos não serem adequados; a primeira com $61(19,5 \%)$ e a segunda com $51(16,3 \%)$ do total de citações feitas. 


\subsection{Sugestões propostas pelos alunos}

Além de fatores que permitiram a avaliação da disciplina, foi solicitada aos alunos a manifestação escrita de sugestões, a fim de serem operadas mudanças visando o aprimoramento. No Quadro 4 constata-se a participação maciça dos alunos, com a maioria deles expressando mais de uma sugestão. As subamostras de 1990 e 1991 foram particularmente profícuas, com 175 e 295 sugestões, respectivamente.

QUADRO 4 - SUGESTÕES PROPOSTAS PELOS ALUNOS, RELATIVAS À DISCIPLINA INFORMÁTICA APLICADA À SAÚDE. RIBEIRÃO PRETO, 1993

\begin{tabular}{|c|c|c|c|c|}
\hline SUGESTÃO & $\begin{array}{c}1989 \\
n\end{array}$ & $\begin{array}{c}1990 \\
\mathrm{n}\end{array}$ & $\begin{array}{c}1991 \\
\mathbf{n}\end{array}$ & $\begin{array}{c}\text { TOTAL } \\
\%\end{array}$ \\
\hline $\begin{array}{l}\text { Reduzir o número de alunos/ } \\
\text { computador. }\end{array}$ & 3 & 29 & 49 & $\begin{array}{c}81 \\
16,4 \\
\end{array}$ \\
\hline $\begin{array}{l}\text { Aumentar o número de aulas } \\
\text { práticas. }\end{array}$ & - & 31 & 46 & $\begin{array}{c}77 \\
15,6\end{array}$ \\
\hline $\begin{array}{l}\text { Melhorar as estratégias de ensino } \\
\text { (discussão em grupo, orientação } \\
\text { mais próxima). }\end{array}$ & 7 & 17 & 43 & $\begin{array}{c}67 \\
13,6\end{array}$ \\
\hline $\begin{array}{l}\text { Aprofundar conteúdo enfatizando } \\
\text { a aplicação da informática na } \\
\text { enfermagem. }\end{array}$ & 1 & 27 & 39 & $\begin{array}{c}67 \\
13,6\end{array}$ \\
\hline $\begin{array}{l}\text { Aprofundar conteúdo enfatizando } \\
\text { a aplicação da informática nas } \\
\text { instituições de saúde. }\end{array}$ & 2 & 19 & 36 & $\begin{array}{c}57 \\
11,6\end{array}$ \\
\hline $\begin{array}{l}\text { Aprofundar o conteúdo relativo ao } \\
\text { funcionamento do computador. }\end{array}$ & 8 & 15 & 31 & $\begin{array}{c}54 \\
11,0 \\
\end{array}$ \\
\hline $\begin{array}{l}\text { Reservar horários livres para } \\
\text { praticar no computador. }\end{array}$ & 4 & 24 & 30 & $\begin{array}{c}55 \\
11,2\end{array}$ \\
\hline $\begin{array}{l}\text { Ser oferecida em mais de um } \\
\text { semestre. }\end{array}$ & - & 13 & 21 & $\begin{array}{l}34 \\
7,0\end{array}$ \\
\hline TOTAL & 25 & 175 & 295 & $\begin{array}{c}495 \\
100,0\end{array}$ \\
\hline
\end{tabular}

* Houve alunos que fizeram mais de uma sugestão 
A sugestão predominante com maior freqüência, 81 (16,4\%) citações, mencionou a redução do número de alunos por computador, e já a partir das críticas notou-se que essa é uma das maiores reivindicações dos alunos, e que no momento já há condições de atender, uma vez que, em fins de 1991, foi instalada na Escola, a sala pró-aluno com equipamentos para seu uso exclusivo.

"Aumentar o número de aulas práticas", com 77 (15,6\%) citações, apareceu como outra sugestão bastante mencionada, embora limitando-se a duas sub-amostras (1990 e 1991). A "melhora das estratégias de ensino", também foi mencionada com uma freqüência significativa, 67 (13,6\%) citações, e nas três sub-amostras (1989, 1990 e 1991). Com o mesmo número de citações que essa sugestão, evidencia-se outra, isto é, "aprofundar o conteúdo enfatizando a aplicação da informática na enfermagem", freqüente, em especial, nas sub-amostras de 1990 e 1991.

As três sugestões que seguem estão relacionadas à: aprofundar o conhecimento das aplicações da informática; nas instituições de saúde e no funcionamento do computador. Também, foi sugerida, a reserva de horários livres para o aluno praticar no computador. Essas sugestões apresentaram-se com uma freqüência de citações muito próxima: 57 (11,6\%), 54 (11,0\%) e 55 (11,2\%), respectivamente. E como última sugestão, evidenciando um número considerável de citações, embora em apenas duas sub-amostras (1990 e 1991), apareceu o oferecimento da disciplina em mais de um semestre, com $34(7,0 \%)$ do total de sugestões mencionadas pelos alunos.

\section{CONSIDERAÇÕES FINAIS}

Parece ser do conhecimento comum a necessidade de se integrar a informática ao processo educativo, a fim de favorecer a construção de um novo saber, contudo, na realidade da educação em enfermagem, poucas mudanças tem sido introduzidas nesse sentido, fato que não deve causar espanto, uma vez que nas Universidade, de maneira geral, os avanços tem ocorrido de maneira restrita (MATA MARIA, 1992).

Outra questão a ser assinalada refere-se ao fato de que o uso dessa tecnologia requer o preparo dos docentes na aquisição de novas habilidades que serão necessárias para viver num meio informatizado e para saber explorar, no seu cotidiano, no mundo do trabalho, as potencialidades que lhe oferece.

Segundo observado neste estudo parece que na percepção dos alunos a introdução da informática na enfermagem é um fato incontestável e que poderá beneficiar a profissão. O quanto isso se constituirá na realidade do cotidiano da prática, é algo ainda a ser observado. O que se tem de concreto, como bem assinala 
(LEÃO; SIGULEN, 1990), é que na sociedade moderna, a informação se apresenta com um recurso básico, "a preponderância do bem informação sobre os outros bens é um fato". E o seu manuseio solicita dos indivíduos novos conhecimentos e o uso de máquinas e programas capazes de tratar adequadamente essas informações. Cabe aos professores romperem com as primeiras barreiras, os medos, principalmente o de ser incapaz ou o de ser substituído pela máquina, bem como os preconceitos, atribuindo ao computador qualidades tais como "ser" alienante, dominador da vontade humana.

Especificamente na enfermagem, pensa-se que ele possa chamar os docentes à reflexão sobre o ensino; como está se dando conta do "saber próprio", da enfermagem e diante disso, como incorporar o "saber novo" da informática, como integrá-lo de maneira mais adequada à prática educacional de enfermagem?

Enquanto responsáveis pela disciplina, mediante os dados obtidos a partir dos alunos, foi possível constatar que há um longo caminho a percorrer até a obtenção de um programa de disciplina mais adequado, bem como de práticas didáticas específicas, mais eficazes para atingir essa clientela. $O$ ter consciência das deficiências e das limitações levou à necessidade de um retorno do aluno, que permitisse detectar mais concretamente, aquilo que os docentes intuíam, a respeito da disciplina que estavam ministrando. As críticas e sugestões foram aceitas com humildade e discussões a esse respeito já estão sendo promovidas.

Parece evidente, que o processo ensino-aprendizagem tende a ocorrer de maneira distinta dos moldes do passado, o docente não é mais a única fonte de informação, tampouco é possível ignorar-se a interferência da informática.

\section{EVALUATION OF A DISCIPLINE ON INFORMATICS BY NURSING UNDERGRADUATE STUDENTS}

This study was undertaken to investigate the opinion of nursing undergraduate students of the first year about the discipline "Informatic applied to health". Data were collected using a questionnaire with open and closed questions applied through three consecutive years (1989, 1990 and 1991). The results showed that undergraduate students considered this course important. Student's expectations were related to the necessity to get familiar with computers. The mentioned critiques were related to the necessity of more time and equipments to support a better learning process.

UNITERMS: nursing, informatics, teaching 


\section{EVALUACIÓN DE UNA DISCIPLINA DE INFORMÁTICA POR ESTUDIANTES DE PREGRADO DE ENFERMERÍA}

Este estudio tuvo el objetivo de investigar la opinión de los alumnos de primer año del Curso de Pre-Grado en Enfermería, respecto a la asignatura "Informática Aplicada a la Salud". Los datos fueron recolectados a través de un cuestionario con preguntas abiertas y cerradas, aplicado en tres años consecutivos $(1989,1990,1991)$. Los resultados han evidenciado que es importante mantener esa asignatura en el Curso de Pre-Grado en Enfermería. Las expectativas de los alumnos están relacionadas con la necesidad de familiarizarse con el computador. Las críticas mencionadas se refieren a solicitudes de más tiempo y equipamientos para hacer efectivo el proceso de aprendizaje.

UNITERMOS: enfermería, informática, enseñanza

\section{REFERÊNCIAS BIBLIOGRÁFICAS}

01. BRASIL. Secretaria Especial de Informática. Proposta de Plano Setorial de Informática em Saúde. Relatório da Comissão Especial, n. 27, Brasília, 1988, p. 88.

02. CYSNEIROS, P.G. Aspectos sociológicos da informática educativa. Tecnol. Educ., Rio de Janeiro, v. 20, n. 102/103, p. 45-8, 1991.

03. GUIMARÃES, S.G. A informática na enfermagem: introduzindo o computador na estratégia de ensino e assistência de enfermagem. Porto Alegre. Dissertação (Mestrado) - Pontifícia Universidade Católica do Rio Grande do Sul, 1988.

04. HELler, B.R., ROMANO, C.A., DAMROSCH, S. P., PARKS, P. Computer applications in nursing: implications for the curriculum. Comput. Nurs., v. 3, n. 1, p. 14-21, 1985.

05.

BRAUN, R. F., MORAY, L. R. The use of a constructivist paradigm for the evaluation of a nursing informatics program. In: WANG, J.F., SIMONI, P.S., NATH, C. L. (eds). Vision of excellence: the decade of the nineties. Proceedings of the West Virginia Nurses' Association 1990. Charleston: West Virginia Nurses' Association, 1990. p. 447-52.

06. LARSON, C. E. Use of the microcomputer $\mathrm{s}$ a tool for subjetive grading. Comput. Nurs., v. 5, n. 5, p. 186-91, 1987.

07. LEÃO, B.F., SIGULEN, D. Por que investir em informática? Ciência Cult., São Paulo, v. 42, n. 5/6, p. 372-4, 1990.

08. LEFFA, V. J. O computador no ensino de línguas: Estado da arte e tendências. Tecnol. Educ., Rio de Janeiro, v. 20, n. 102-103, p. 23-8, 1991. 
09. MATA MARIA, L. Informática na educação: realismo e utopia. Tecnol. Educ., Rio de Janeiro, v. 21, n. 105-106, 1992.

10. MIRIN, S. The computers place in nursing education. Nurs. Health Care, Wesport, v. 2, n. 9, p. 500-6, 1981.

11. SANTOS, B.R.L. et al. O ensino de atenção primária à saúde: avaliação diagnóstica e formativa através de microcomputadores. Rev. Gaúch. Enfermagem, Porto Alegre, v. 13, n. 2, p. 5-10, 1992.

12. VITALE, B. O computador na escola: um brinquedo a mais? Ciência Hoje, Rio de Janeiro, v. 13, n. 77, p. 18-25, 1991. 